\title{
KNEE ARTHROPLASTY REVISION WITH A CONSTRAINED IMPLANT USING HINGE AND ROTATING TIBIAL BASIS
}

\author{
Fabio Jansen Angelin ${ }^{1}$, Camilo Partezani Helito ${ }^{1}$, Bruno Azevedo Veronesi ${ }^{1}, T_{\text {ales Mollica Guimarães }}{ }^{1}$, \\ José Ricardo Pécora ${ }^{1}$, Marco Kawamura Demange ${ }^{1}$
}

1. Universidade de São Paulo, Faculdade de Medicina, Department of Orthopedics and Traumatology, Knee Surgery Group, São Paulo, SP, Brasil.

\section{ABSTRACT}

Objective: To evaluate the results of total knee arthoplasty revisions performed in high complexity cases, with large bone defects or serious ligament deficiencies using a constrained implant hinge associated to a rotating tibial basis. Methods: We evaluated 11 patients in which we used the constrained implant hinge associated to rotating tibial basis, with minimum follow-up of two years. The indications for the procedure included instability, septic loosening, late postoperative infection without loosening and periprosthetic fracture. We evaluated the knee range of movement and functional outcomes by the Knee Society Score (KSS) e Knee Injury and Osteoarthritis Outcome
Score (KOOS), besides the presence of complications. Results: All patients achieved $5^{\circ}$ to $85^{\circ}$ minimum range of motion at 1 year postoperatively and, in the present evaluation, KSS ranged from 67 to 95. Three patients had no complications until the last evaluation and two patients required implant revision. Conclusion: Despite the complications rate observed, the functional result were acceptable for most patients, and it proved being a viable alternative, especially for patients with low functional demand. Level of Evidence IV, Case Series.

Keywords: Arthroplasty, replacement, knee. Prostheses and Implants.

Citation: Angelini FJ, Helito CP, Veronesi BA, Guimarães TM, Pécora JR, Demange MK. Knee arthroplasty revision with a constrained implant using hinge and rotating tibial basis. Acta Ortop Bras. [online]. 2016;24(1):22-6. Available from URL: http://www.scielo.br/aob.

\section{INTRODUCTION}

Due to the aging of the population and consequently the increase of patients osteoarthritis, indication of total knee arthroplasty (TKA) is increasingly frequent. ${ }^{1}$ This procedure shows excellent postoperative results regarding survival of the implant, with rates over $95 \%$ in at least 10 years follow-up. ${ }^{2-5}$ However, a small portion of TKA show failure over time, needing revison. ${ }^{6}$ These failures are characterized by pain, functional disability of the knee and/or radiographic evidence of release of one or more components. ${ }^{7}$ With the increased life expectancy and a larger number of primary surgeries, consequently, a larger quantity of revision surgeries must be performed. Kurtz et al. ${ }^{8}$ estimate that TKA revisions in the USA will increase $600 \%$ by 2030 . According to the National Center of Health Statistics 381,000 TKA were carried out in 2003 in the USA, and according to the American Association of Orthopedic Surgeons (AAOS), and 475,000 shall be performed by 2030. In 2003 35,000 revision TKA surgeries were performed, i.e. $9 \%$ of all arthroplasties were revision surgeries. For 2030 it is estimated that 43,500 revision surgeries will take place in the USA. ${ }^{9}$ On failure of a primary TKA, revision surgery is performed, usually, with intramedullary nails among the components to increase the stability of the femoral and tibial implants, besides metal wedges for filling of bone defects. In major failures, structured allograft or trabecular metal wedges can also be used. ${ }^{10}$

In cases of large bone defects with loss of ligament insertions on the femur or tibia, significant ligament insufficiencies or gross imbalance between the extension and flexion spaces, conventional revision implants do not promote stability in appropriate varus-valgus, making the revision arthroplasty unstable. ${ }^{11}$ As a solution to this problem, hinge type arthroplasty systems have been developed with excellent results in recent studies. ${ }^{12-15}$ Complex systems, however, are not always available in all countries due to their high cost and difficulty to import from foreign countries, therefore, complex revision cases should be solved with locally available implants in order to avoid non-conventional tumor prosthesis. ${ }^{16}$ The hinge implant associated with a rotating tibial basis (Figures 1 and 2) is proposed as a possible cost effective solution for knee revision arthroplasty with large bone loss or gross ligamentous instability.

The aim of this study was to evaluate the results, with at least two years follow-up, of TKA revisions performed with hinge implant associated to a rotating tibial basis in high complexity cases.

All the authors declare that there is no potential conflict of interest referring to this article.

Work develpoed at Universidade de São Paulo, Faculdade de Medicina, Department of Orthopedics and Traumatology, Laboratory of Medical Investigation of the Musculoskeletal System, São Paulo, SP, Brazil.

Correspondence: Rua Dr. Ovídio Pires de Campos, 333. São Paulo, SP, Brazil. 05403-010. tales92@gmail.com

Article received in 09/02/2015, approved in 09/03/2015 


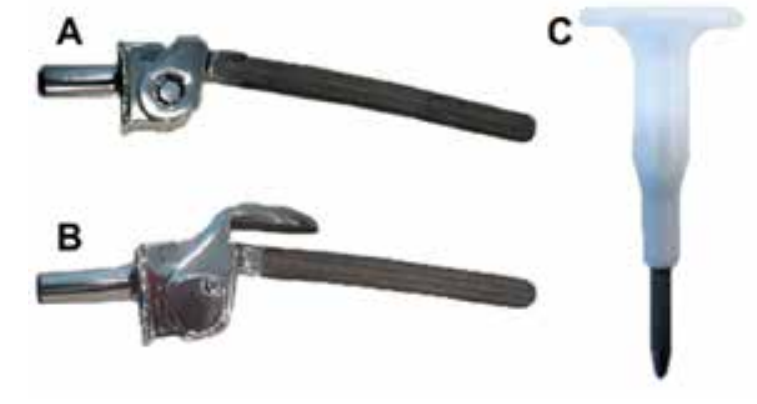

Figure 1. Hinge implant associated with rotating tibial basis (IMPOL, São Bernardo, SP, Brazil). A) Hinge; B) Hinge with shed; C) Tibial base.

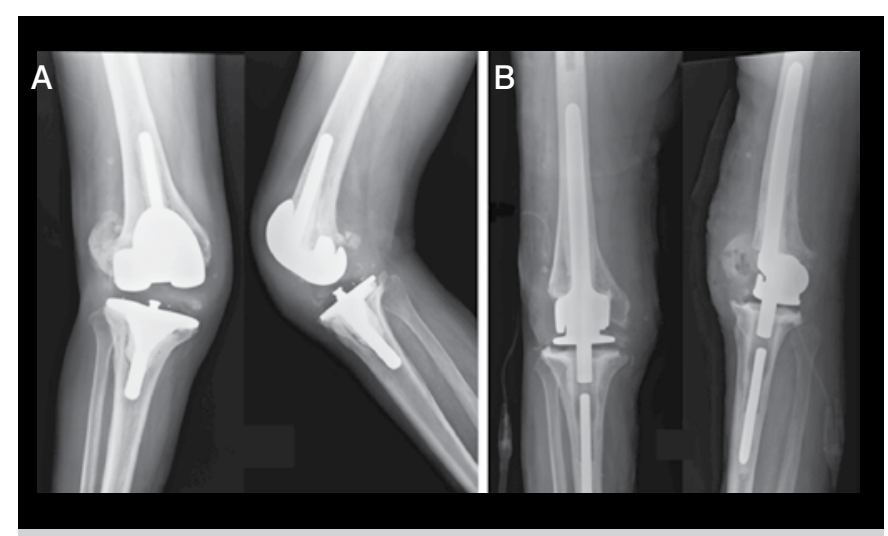

Figure 2. A) Seventy two year old patient revision prosthesis held in 2012 at another service, with late postoperative infection associated with ligament failure; B) Patient was subjected to implant removal and spacer placement and subsequent revision implant with hinge associated to rotating tibial base. After 1 year postoperatively patient presented range of motion $0^{\circ}-110^{\circ}$

\section{MATERIALS AND METHODS}

Patients who underwent TKA revision using hinge associated to rotating tibial basis (IMPOL, São Bernardo, SP, Brazil), between 2003 and 2013 were retrospectively evaluated.

The study was approved by the Scientific Committee of the Department of Orthopedics and Traumatology of the institutions (protocol number 1130). Patients were called for clinical evaluation update and oriented on the study. All participants signed a Free and Informed Consent Term.

Patients who met the following criteria were included: those undergoing knee arthroplasty review with hinge implant associated with tibial rotational basis, any age and gender and with at least two years of follow-up. Exclusion criteria were: lack of data in medical records that made it impossible to fill the desired information, not signing or not understanding the Free and Informed Consent.

Information collected from medical records included age, gender, comorbidities, reason to indication and date of surgery, laterality, knee range of motion in the postoperative follow-up and complications in the postoperative period.

Information collected from patients included clinical and functional evaluation by applying the Portuguese version (KSS-pt) of the Knee Society Score ${ }^{17}$ and the Portuguese version of Knee Injury and Osteoarthritis Outcome Score (KOOS-pt). ${ }^{18}$

\section{RESULTS}

During the period from 2003 to 2013, 14 patients underwent revision knee arthroplasty with hinge implant associated with rotating tibial basis three of which were excluded due to missing data in the medical records and patients' unavailability to perform clinical evaluation update. Among the eleven patients included in the study, six were male and five female, with mean age at time of surgery of 70 years old (range $53-83$ years old). (Table 1)

In all cases included in the study, indication of the aforementioned implant was due to large bone defects with loss of ligament insertions on the femur or tibia after removal of previous primary or revision knee arthroplasty, considered type III, according the classification of bone defects in the knee developed by the Anderson Orthopedic Research Institute (AORI). ${ }^{19}$ The cause of arthroplasty removal was septic loosening in four cases (36\%), late infection in five cases (45\%), instability in one case (9\%), and one case $(9 \%)$ of a periprosthetic fracture in a patient who already had septic loosening of TKA and was awaiting revision surgery. Of the four cases of loosening, three were already revision implants. (Table 2)

Three patients presented with no complications until the last evaluation. One patient had a positive intraoperative culture and was treated with antibiotics for six months. One patient presented with erysipelas in the first postoperative month and was also treated with antibiotics; this patient had an acute late postoperative infection after two years, being treated with a single surgical cleaning and evolving well. Two patients had

\begin{tabular}{|c|c|c|c|c|c|}
\hline Patient & $\begin{array}{c}\text { Age at } \\
\text { surgery } \\
\text { (years old) }\end{array}$ & $\begin{array}{c}\text { Current age } \\
\text { (years old) }\end{array}$ & Gender & Comorbidities & Side \\
\hline 1 & 65 & 77 & $\mathrm{~F}$ & SAH & $\mathrm{R}$ \\
\hline 2 & 59 & 66 & M & RA, glaucoma, cataract & $\mathrm{R}$ \\
\hline 3 & 77 & 84 & $\mathrm{~F}$ & None & $L$ \\
\hline 4 & 83 & 90 & $\mathrm{~F}$ & AF & $\mathrm{R}$ \\
\hline 5 & 77 & 82 & M & $\mathrm{SAH}, \mathrm{COPD}, \mathrm{RA}$ & $\mathrm{R}$ \\
\hline 6 & 82 & 87 & $\mathrm{~F}$ & SAH, cardiomyopathy & $L$ \\
\hline 7 & 74 & 77 & $\mathrm{~F}$ & SAH, cardiomyopathy & $L$ \\
\hline 8 & 66 & 68 & M & SAH, RA & $\mathrm{R}$ \\
\hline 9 & 53 & 55 & M & None & $\mathrm{R}$ \\
\hline 10 & 71 & 73 & M & SAH, Parkinson, DLP & $\mathrm{R}$ \\
\hline 11 & 61 & 63 & M & none & $\mathrm{R}$ \\
\hline Mean & 70 & 75 & & & \\
\hline SD & 9,34 & 10,38 & & & \\
\hline
\end{tabular}

SAH: Systemic arterial hypertension; DLP: Dyslipidemia; RA: Rheumatoid arthritis; AF: Atrial fibrillation; COPD: Chronic obstructive pulmonary disease; SD: Standard deviation. 
acute postoperative infection in less than one month after surgery and were treated with surgical cleaning; one of them required gastrocnemius flap rotation for covering after debridement; the two had good evolution without remission of infection. One patient developed acute postoperative infection that required implant removal and evolved into transfemoral amputation of the affected limb. One patient, also with acute postoperative infection, underwent several surgical cleanings, but evolved with septic shock and died. Two patients had complications related to the implant integrity following trauma; one suffered a fall one year later and presented breach of the polyethylene rotatory tibial basis, requiring implant revision(Figure 3); another patient also suffered a fall three years later, progressing to breakage of the tibial component stem and needed revision surgery. (Table 2)

\begin{tabular}{|c|c|c|c|c|}
\hline Patient & Indication & Complication & $\begin{array}{c}\text { Postoperative } \\
\text { period }\end{array}$ & $\begin{array}{l}\text { Treatment / } \\
\text { Evolution }\end{array}$ \\
\hline 1 & Instability & None & -- & --- \\
\hline 2 & $\begin{array}{l}\text { Late } \\
\text { postoperative } \\
\text { infection }\end{array}$ & $\begin{array}{l}\text { Postoperative } \\
\text { infection }\end{array}$ & $\begin{array}{c}1 \text { month - } \\
1 \text { year }\end{array}$ & $\begin{array}{l}\text { Implant removal; } \\
\text { transfemoral } \\
\text { amputation }\end{array}$ \\
\hline \multirow{2}{*}{3} & $\begin{array}{l}\text { Late } \\
\text { postoperative } \\
\text { infection }\end{array}$ & Erysipelas & $<1$ month & Antibiotics \\
\hline & $\begin{array}{l}\text { Septic } \\
\text { loosening }\end{array}$ & $\begin{array}{l}\text { Postoperative } \\
\text { infection }\end{array}$ & $>1$ year & Surgical cleaning \\
\hline 4 & $\begin{array}{l}\text { Late } \\
\text { postoperative } \\
\text { infection }\end{array}$ & $\begin{array}{l}\text { Breaking of the } \\
\text { tibial component }\end{array}$ & $>1$ year & $\begin{array}{l}\text { Revision of the } \\
\text { tibial component }\end{array}$ \\
\hline 5 & $\begin{array}{c}\text { Septic } \\
\text { loosening }\end{array}$ & $\begin{array}{l}\text { Postoperative } \\
\text { infection }\end{array}$ & $<1$ month & Surgical cleaning \\
\hline 6 & $\begin{array}{l}\text { Septic loosening } \\
+ \text { periprosthetic } \\
\text { fracture }\end{array}$ & None & $\cdots$ & -- \\
\hline 7 & $\begin{array}{l}\text { Septic } \\
\text { loosening }\end{array}$ & None & $\cdots$ & $\cdots$ \\
\hline 8 & $\begin{array}{l}\text { Late } \\
\text { postoperative } \\
\text { infection }\end{array}$ & $\begin{array}{l}\text { Postoperative } \\
\text { infection }\end{array}$ & --. & $\begin{array}{c}\text { Surgical cleaning; } \\
\text { death }\end{array}$ \\
\hline 9 & $\begin{array}{l}\text { Septic } \\
\text { loosening }\end{array}$ & $\begin{array}{l}\text { Breaking of the } \\
\text { polyethylene }\end{array}$ & $\begin{array}{c}1 \text { month - } \\
1 \text { year }\end{array}$ & Implant revision \\
\hline 10 & $\begin{array}{l}\text { Late } \\
\text { postoperative } \\
\text { infection }\end{array}$ & $\begin{array}{l}\text { Intra-operative } \\
\text { culture positive }\end{array}$ & $<1$ month & Antibiotics \\
\hline 11 & Instability & $\begin{array}{l}\text { Postoperative } \\
\text { infection }\end{array}$ & $<1$ month & $\begin{array}{l}\text { Surgical cleaning } \\
\text { and rotation of } \\
\text { gastrocnemius flap }\end{array}$ \\
\hline
\end{tabular}

The present surgery follow-up period ranged from two to twelve years. KSS-pt varied from 67 to 95 points. KOOS-pt ranged from 27 to 35 regarding pain, 50-60 for activities of daily living, 0-2 for sport and leisure, 3-12 for quality of life, and 21-28 for other symptoms. (Table 3)

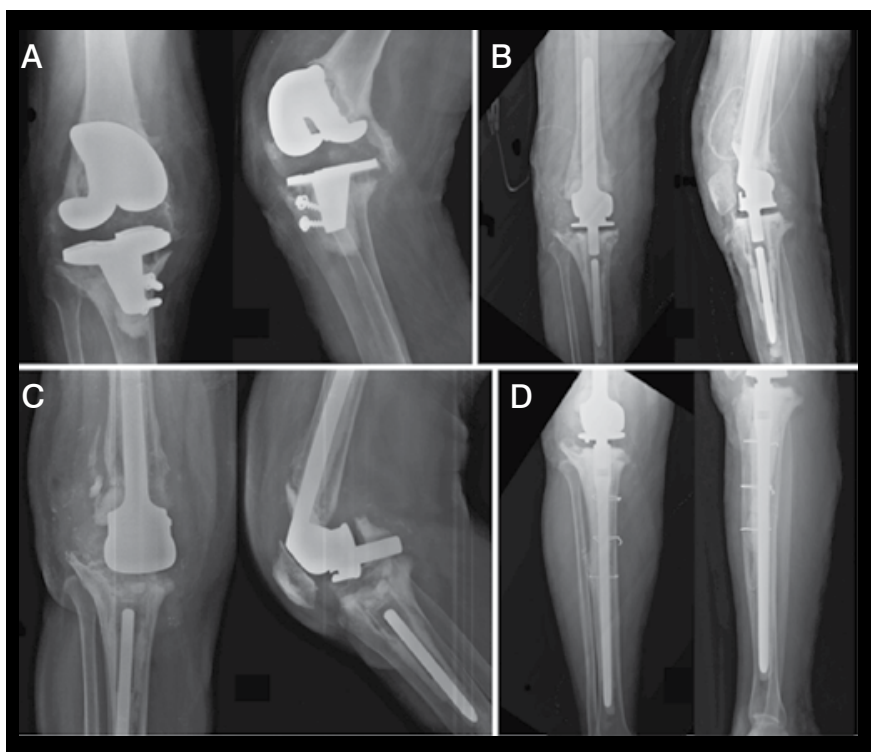

Figure 3. A) Fifty five year old patient with septic loosening of TKA performed at another service; B) Patient underwent implant removal with spacer placement and further review with hinge associated with rotating tibial basis; C) Patient suffered falling to the ground, breaking the polyethylene tibial base; D) Patient submitted to revision of the tibial component with a long shaft.

Table 3. Clinical-functional assessment

\begin{tabular}{|c|c|c|c|c|c|c|c|c|c|c|}
\hline \multirow{2}{*}{ Patient } & \multicolumn{3}{|c|}{ ROM at the first year } & \multirow{2}{*}{$\begin{array}{c}\text { Years } \\
\text { PO }\end{array}$} & \multirow{2}{*}{ KSS-PT } & \multicolumn{5}{|c|}{ KOOS-PT } \\
\hline & $\begin{array}{c}1 \\
\text { month }\end{array}$ & $\begin{array}{c}6 \\
\text { months }\end{array}$ & $\begin{array}{c}1 \\
\text { year }\end{array}$ & & & Pain & DLA & SL & QL & 0 \\
\hline 1 & $5-90^{\circ}$ & $5-90^{\circ}$ & $5-90^{\circ}$ & 12 & 85 & 34 & 57 & 0 & 10 & 26 \\
\hline 2 & --- & --- & -- & 7 & \multicolumn{6}{|c|}{ Amputee } \\
\hline 3 & $10-90^{\circ}$ & $0-85^{\circ}$ & $0-85^{\circ}$ & 7 & 67 & 27 & 50 & 0 & 3 & 23 \\
\hline 4 & $0-90^{\circ}$ & $0-90^{\circ}$ & $0-90^{\circ}$ & 7 & 85 & 33 & 55 & 0 & 4 & 25 \\
\hline 5 & $0-55^{\circ}$ & $0-100^{\circ}$ & $0-100^{\circ}$ & 5 & 95 & 35 & 52 & 0 & 12 & 28 \\
\hline 6 & $0-15^{\circ}$ & $0-90^{\circ}$ & $0-90^{\circ}$ & 5 & 85 & 30 & 54 & 0 & 6 & 23 \\
\hline 7 & $0-90^{\circ}$ & $0-85^{\circ}$ & $0-85^{\circ}$ & 3 & 88 & 33 & 60 & 1 & 11 & 27 \\
\hline 8 & --- & -- & --- & --- & \multicolumn{6}{|c|}{ Death } \\
\hline 9 & $0-90^{\circ}$ & $0-90^{\circ}$ & $0-90^{\circ}$ & 2 & 83 & 32 & 59 & 1 & 5 & 21 \\
\hline 10 & $0-45^{\circ}$ & $0-90^{\circ}$ & $0-110^{\circ}$ & 2 & 94 & 36 & 38 & 2 & 8 & 25 \\
\hline 11 & $5^{\circ}-95^{\circ}$ & $5-90^{\circ}$ & $5-90^{\circ}$ & 2 & 87 & 34 & 58 & 2 & 8 & 27 \\
\hline
\end{tabular}

ROM: Range of movement; PO: Postoperative; DLA: Daily life activities; SL: Sports and leisure; QL: Quality of life; O: Other symptoms. 


\section{DISCUSSION}

The amount of TKA revision surgeries is increasing due to increased life expectancy and the higher number of primary surgeries performed. ${ }^{8}$ Hinge type contrite implants with rotating components are a good option for TKA revision where there is significative bone loss and ligament instability. ${ }^{12-15,20,21}$ Sanguineti et al., ${ }^{12}$ with 20 cases of TKA revision surgeries using the Endo-Model rotating-hinge prosthesis (Waldemar Link $\mathrm{GmbH}$ and Co., Hamburg, Germany), Neumann et al. ${ }^{22}$, with 24 cases using the NexGen Rotating Hinge Knee (Zimmer Biomet Inc., Warsaw, IN, USA) and Bistolfi et al. ${ }^{14}$ with 50 cases also using the Endo-Model prosthesis, are some of the largest series showing the follow-up of patients submitted to TKA revision with this type of implant. These implants, however, although also of the hinge type, have a quite different design than the implants used in this study. Similarly to our study, the indications for revision TKA in these studies ranged from postoperative infection, implant loosening and periprosthetic fracture.

Sanguineti et al. ${ }^{12}$ reported 20 cases with five years follow-up, with only two complications in the period, a dislocation of the implant by trauma occurred in rehabilitation and a deep infection. Neumann et al. ${ }^{22}$ reported 20 cases with a minimum follow-up of 36 months. There were two cases in which there were radiolucent lines around the tibial component and a case of patellofemoral subluxation, which was treated with revision of the patellar component, lateral release and advance of the vastus medialis.

The work of Bistolfi et al. ${ }^{14}$ was the series with more cases and longer follow-up: 50 cases, of which 34 had minimum follow-up of 150 months. As early complications the authors observed four cases of wound dehiscence, two cases of hematoma and two cases of infection, the latter treated with debridement, polyethylene exchange and antibiotics. As late complications, nine cases of polyethylene breaking were observed. In three cases, revision of the implant was necessary due to generated instability. In both cases, the polyethylene wear and breakage occurred due to dislocation and in one case, due to septic loosening. In the other three cases the damage to the polyethylene was asymptomatic and the conduct was conservative. There were two cases of poor functional outcome - a case of injury to the extensor mechanism and one case of septic loosening - treated conservatively due to poor clinical condition of the patients. ${ }^{14}$

The complication rate in our study was high. The most frequent complication diagnosed was postoperative infection, which can be attributed to the following factors: approximately $45 \%$ of patients had revision surgery indicated by septic loosening; the profile of the enrolled patients (advanced age, ill health and previous comorbidities, lower social and instruction level). Still, most patients who developed infection were treated successfully with surgical cleaning and proper use of antibiotics. Because ours is a reference service for high complexity cases, most patients with poor functional outcomes or arthroplasty failures ended up being referred to our hospital, therefore, most of the cases that were reviewed due to infection presented the primary condition in a different service.

In two cases there was breakage of the implant component. We believe that, in these cases, failure of the implant was due to fatigue caused by increased stress due to ligament absence, in which the stress transfer in the bone-cement-implant interface is high. In recent studies, which used more developed implant models, this was not a frequent complication. ${ }^{13,14,22}$ Because of this potential complication, we advise all patients to use, postoperative, continuous and permanent support to walk (e.g. a cane), in order to provide maximum protection for the operated limb and the implant.

Due to the shape of the implant, which has the anterior part of the femoral component squared, we frequently observed dislocation of the patella upon knee flexion intraoperatively. A lateral wide release was necessary in all cases to fix the patellar tracking. Nevertheless, none of the patients assessed complained of pain in the anterior knee and all managed at least $85^{\circ}$ flexion after one year postoperatively, showing that the potential increase of patellofemoral pressure did not lead to loss of range of motion.

The mean age in our study was high (70 years), similarly to the literature. Older patients showed generally good results regarding the expectations of performing activities of daily living, quality of life, and little complaint about symptoms such as pain, instability or stiffness. The presented functional outcomes can be considered acceptable for patients with low functional demands, but for patients with moderate to high functional demands, the implant may not match the treatment expectations. Nevertheless, in our series, five patients were younger than 70 years old at time of surgery and three of them who could be evaluated had KSS greater than 80 .

The limitations of this study were its retrospective nature and low number of patients. Anyway, due to shortage of implants for the treatment of instabilities and coarse bone loss in our midst, as well as the relatively small number of complications, it is important to know the functional outcome of patients using simple design constricted articulated hinge implants associated to rotating tibial basis.

\section{CONCLUSION}

In the absence of newer design implants, the constricted hinge implant associated to rotating tibial base is a viable option for revision TKA where there is significant bone loss and ligamentous instability, especially in patients with low functional demand. Despite the observed complications rate, the functional outcome was considered acceptable for most patients. 


\section{REFERENCES}

1. Jamsen E, Jantti P, Puolakka T, Eskelinen A. Primary knee replacement for primary osteoarthritis in the aged: gender differences in epidemiology and preoperative clinical state. Aging Clin Exp Res. 2012;24(6):691-8.

2. McLaughlin JR, Lee KR. Hybrid total knee arthroplasty: 10- to 16-year follow-up. Orthopedics. 2014;37(11):e975-7.

3. Kim YH, Park JW, Kim JS, Kulkarni SS, Kim YH. Long-term clinical outcomes and survivorship of press-fit condylar sigma fixed-bearing and mobile-bearing total knee prostheses in the same patients. J Bone Joint Surg Am. 2014;96(19):e168.

4. Ritter MA, Berend ME, Meding JB, Keating EM, Faris PM, Crites BM. Long-term followup of anatomic graduated components posterior cruciate-retaining total knee replacement. Clin Orthop Relat Res. 2001;(388):51-7.

5. Ranawat CS, Flynn WF Jr., Saddler S, Hansraj KK, Maynard MJ. Long-term results of the total condylar knee arthroplasty. A 15-year survivorship study. Clin Orthop Relat Res. 1993;(286):94-102.

6. Healy WL, Della Valle CJ, lorio R, Berend KR, Cushner FD, Dalury DF, et al. Complications of total knee arthroplasty: standardized list and definitions of the Knee Society. Clin Orthop Relat Res. 2013;471(1):215-20.

7. Jacofsky DJ, Della Valle CJ, Meneghini RM, Sporer SM, Cercek RM, American Academy of Orthopaedic S. Revision total knee arthroplasty: what the practicing orthopaedic surgeon needs to know. J Bone Joint Surg Am. 2010;92(5):1282-92.

8. Kurtz S, Ong K, Lau E, Mowat F, Halpern M. Projections of primary and revision hip and knee arthroplasty in the United States from 2005 to 2030. J Bone Joint Surg Am. 2007;89(4):780-5.

9. Burns AW, Bourne RB, Chesworth BM, MacDonald SJ, Rorabeck CH. Cost effectiveness of revision total knee arthroplasty. Clin Orthop Relat Res. 2006;(446):29-33.

10. Beckmann NA, Mueller S, Gondan M, Jaeger S, Reiner T, Bitsch RG. Treatment of severe bone defects during revision total knee arthroplasty with structural allografts and porous metal cones-a systematic review. J Arthroplasty. 2015;30(2):249-53.
11. McNabb DC, Kim RH, Springer BD. Instability after total knee arthroplasty. J Knee Surg. 2015;28(2):97-104.

12. Sanguineti F, Mangano T, Formica M, Franchin F. Total knee arthroplasty with rotating-hinge Endo-Model prosthesis: clinical results in complex primary and revision surgery. Arch Orthop Trauma Surg. 2014;134(11):1601-7.

13. Gehrke T, Kendoff D, Haasper $C$. The role of hinges in primary total knee replacement. Bone Joint J. 2014;96-B(11 Suppl A):93-5.

14. Bistolfi A, Rosso F, Crova M, Massazza G. Endo-Modell rotating-hinge total knee for revision total knee arthroplasty. Orthopedics. 2013;36(10):e1299-306.

15. Bistolfi A, Massazza G, Rosso F, Crova M. Rotating-hinge total knee for revision total knee arthroplasty. Orthopedics. 2012;35(3):e325-30.

16. Biau D, Faure F, Katsahian S, Jeanrot C, Tomeno B, Anract P. Survival of tota knee replacement with a megaprosthesis after bone tumor resection. J Bone Joint Surg Am. 2006;88(6):1285-93.

17. Silva AL, Demange MK, Gobbi RG, da Silva TF, Pecora JR, Croci AT. Translation and validation of the Knee Society Score - KSS for Brazilian Portuguese. Acta Ortop Bras. 2012;20(1):25-30.

18. Goncalves RS, Cabri J, Pinheiro JP, Ferreira PL. Cross-cultural adaptation and validation of the Portuguese version of the Knee injury and Osteoarthritis Outcome Score (KOOS). Osteoarthritis Cartilage. 2009;17(9):1156-62.

19. amaguchi MM, Helito CP, Gobbi RG, Demange MK, Tirico LEP, Pecora JR, et al. Valor da avaliação radiográfica pré-operatória dos defeitos ósseos no joelho nas revisões de artroplastia. Rev Bras Ortop. 2012;47(6):714-8.

20. Nelson CL, Gioe TJ, Cheng EY, Thompson RC Jr. Implant selection in revision total knee arthroplasty. J Bone Joint Surg Am. 2003;85(Suppl 1):S43-51.

21. Pradhan NR, Bale L, Kay P, Porter ML. Salvage revision total knee replacement using the Endo-Model rotating hinge prosthesis. Knee. 2004;11(6):469-73.

22. Neumann DR, Hofstaedter T, Dorn U. Follow-up of a modular rotating hinge knee system in salvage revision total knee arthroplasty. J Arthroplasty. 2012;27(5):814-9. 